\title{
An Error Analysis on The Use of Past Tense in Narrative Text Translation of SMA Students
}

\author{
Indira Wijayanti Halim, Abdul Asib, Sujoko \\ English Education Department \\ Teacher Training and Education Faculty \\ Sebelas Maret University of Surakarta
}

Email: indirahalim@yahoo.com

\begin{abstract}
This article describes the errors that students committed on the use of past tense in narrative text translation. The purpose is to reveal the common errors in using past tense in narrative translation made by the eleventh grade students at one of state senior high school in Surakarta. In this research, the researcher used descriptive method. The study focused on the difficulty in using past tense in narrative text translation. The techniques of collecting the data used in this research are using test and questionnaire. The qualitative data were analyzed by identifying the data of errors, describing the errors and classifying into the types of errors, explaining the errors based on the error sources, and evaluating the errors. Based on the result of the research, the total error is 465 errors. First, the errors based on the indicators are: error on the use of V2, error of time marker, error of modal auxiliaries, and error of helping verb. The highest frequency of error is error on the use of V2 (390/ 83.87\%). Then the lowest frequency of error is error of time marker $(1 / 0.22 \%)$. Second, the errors based on the causes of errors are omission (absence of an item that must appear in a well-formed utterance), addition (characterized the presence of an item, which must not appear in a well-formed utterance), and overgeneralization (the learner creates a deviant structure on the basis of other structures).The highest frequency of error is omission (104/56.52\%), and the lowest frequency of error is addition (36/ $19.57 \%)$.
\end{abstract}

Keywords: error analysis, past tense, types and causes of errors.

\section{INTRODUCTION}

Commonly, learning English is focused on learning about the language itself. Referring to Corder (1973: 19) language is a very complex thing, and it cannot yet be fully accounted for by anyone within one wholly consistent thing and comprehensive theory.

The students learn about the form, function and the use of the language. They learnt grammar, vocabulary, pronunciation, et cetera. In the end of the lesson, the students are expected to be able to communicate using English in spoken or written form. It needs to be realized that the English ability of most students are still far from being perfect. It can be seen from the limitation of their capability in using English in real communication. The limitation and low capability in English, however, indicates the goals of English teaching and learning in school have not successfully achieved yet. In this case, the students are not truly engaged in the teaching and learning process. They only depend on the teacher to direct all learning and to be the source of the information. 
Learning the second language is different from learning first language. Therefore, the students often made errors while the teaching learning process. For the foreign language, the students can get new rules of language, vocabulary, grammatical patterns and pronunciation.

Different from their language, the error is natural for the students in learning the second language, because English is the second language. Here are some definitions of error. According to Corder (1973: 268) the assumption underlying the description of errors is that they are evidence of a system of some other language. Jeremy harmer stated, "The errors are part of the learner Interlingua that is the version of the language which a learner has at any one stage of development and which is continually reshaped as he/she aims toward full mastery.

Brown (1987:206) states the fact that learners do make errors and that these errors can be observed, analyzed, and classified to reveal something of the system operating within the learner, led to a surge of study of learners ${ }^{e e}$ errors, called error analysis. Error analysis became distinguished from contrastive analysis by its examination of errors attributable to all possible sources, not just those which result from negative transfer of the native language.

An error analysis is important to describe what kinds of error that the students make, to know the causes of the error and how the students can learn from their mistakes and correct in their translation. Because every students will not make the same errors when they study, the teacher must be able to analyze the errors, because by that, the teacher able to correct the method while he is teaching.

There are two utterances that have almost the same meaning ,error and mistake ${ }^{e e}$. It is important to differentiate between error and mistake. Otherwise, some people are still misunderstanding about the definition of them. To clarify between error and mistake, Brown (1987:205) says, "A mistake refers to a performance error that is either a random guess or a "slip," in that it is failure to utilize a known system correctly. All people make mistakes, in both native and second language situations. Besides an error is a noticeable deviation from the adult grammar of a native speaker, reflecting the inter-language competence of learner.

Referring to Ellis (1997: 17) the difference of errors and mistakes is errors reflect gaps in a learner"s knowledge; they occur because the learner does not know what is correct. Mistakes reflect occasional lapses in performance; they occur because, in a particular instance, the learner is unable to perform what he or she knows.

In conclusion it is different between mistake and error. Mistake relate with performance. Students have known about the lesson but they forget whereas error relates with competence. Students never have known about the lesson so they cannot do the exercise.

Second language acquisition is the process by which people learn a second language. To know the relation between error analysis and second language there are some explanations about error analysis in second language acquisition.

It said the strong version involved predicting errors in second language learning based upon an a priori contrastive analysis of the first language and second language, and as we have seen, the predictions are not always borne out. In the weak version, however, researchers start with learner errors and explain at least a subset of them by pointing to the similarities 
and differences between the two languages. (Freeman and Long 1991: 57)

To analyze how far learners ${ }^{\text {ee }}$ ability in using second language is, the researchers could use error analysis. By focusing only on errors, the researchers were denied access to the whole picture. They studied what learners were doing wrong, from the study we could mention errors the learnerse committed, conclude the ability of the learners in using second language and give some advises for the learners and the teachers.

It stated error can be classified into four categories: omission of some required element; addition of some unnecessary or incorrect element; selection of an incorrect element; and misordering of elements. (Corder, 1993: 277)

According to Ellis (1997: 19) some errors seem to be universal, reflecting learners ${ }^{\text {ee }}$ attempts to make the task of learning and using the second language simpler. Learners commit errors of omission. For example, they leave out the articles "ae and ,the ${ }^{\text {ee }}$ and leave the $-\mathrm{s}$ off plural nouns. They also overgeneralize forms that they find easy to learn and process. The use of ,eated ${ }^{\text {ee }}$ in place of ,ate ate $^{\text {ee }}$ is an example of overgeneralization error. Both errors of omission and overgeneralization are common in the speech of all second language learners, irrespective of their first language. Other errors, however, reflect learners ${ }^{\text {ee }}$ attempts to make use of their first language knowledge. These are known as transfer errors.

It said a surface strategy taxonomy of errors (categories and examples taken from Dulay, Burt, and Krashenin Ellis 1994: 56) such as omissions (the absence of an item that must appear in a well-formed utterance), for example "She sleeping", Additions (the presence of an item that must not appear in well-formed utterance), for example "We didn't went her", Misinformations (the use of the wrong form of the morpheme or structure), for example "The dog ated the chicken", Misorderings (the incorrect placement of a morpheme or group of morphemes in an utterance, for example What daddy is doing ?

From the causes of error above, in fact translation is difficult, because it is not only vocabulary and grammatical patterns but also the capability to express the students desire on the paper and able use their own language. The researcher determines there are three errors included in error analysis of past tense narrative text translation such as: omission, addition and overgeneralization.

There are some procedures of error analysis. The steps taken from Corder in Ellis (1994: 49-63) are (1) Collection of a sample of learner language. The starting point in error analysis is deciding what samples of learner language to use for the analysis and how to collect these samples. We can identify three broad types of error analysis according to the size of the sample. A massive sample involves collecting several samples of language use from a large number of learners in order to compile a comprehensive list of errors, representative of the entire population. (2) Identification of errors. Once a corpus of learner language has been collected, the errors in the corpus have to be identified. It is necessary to decide, therefore, what constitutes an ,error ${ }^{\text {ce }}$ and to establish a procedure for recognizing one.(3) Description of errors. The description of learner errors involves a comparison of the learner's idiosyncratic utterances with a reconstruction of those utterances in the target language. Some researchers have felt the need to maintain a clear distinction description and explanation of errors. Dulay, Burt, and Krashen (1982), 
for example, argue the need for descriptive taxonomies of errors that focus only on observable, surface features errors, as a basis for subsequent explanation. (4) Explanation of errors. Explanation is concerned with establishing the source of error, accounting for why it was made. This stage is the most important in second language acquisition research as it involves an attempt to establish the processes responsible for second language acquisition. (5) Evaluating the errors. Whereas all the preceding stages of error analysis have involved an examination of errors from the point of view of the learner who makes them, error evaluation involves a consideration of the effect that errors have on the person(s) addressed. This effect can be gauged either in terms of the addressee ${ }^{\text {ec }} \mathrm{s}$ comprehension of the learneres meaning or in terms of the addressee $\mathrm{s}$ affective response to the errors. Errors evaluation studies proliferated in the late 1970s and in the 1980s. Many studies do not include the evaluation of errors step and, in fact, the evaluation of learner errors was has generally been handled as a separate issue, with its own methods enquiry. Many studies do not include the evaluation of errors step and, in fact, the evaluation of learner errors was has generally been handled as a separate issue, with its own methods enquiry.

\section{RESEARCH METHODS}

According to Nawawi (1996: 9) method is a science about method that if assembled to be a research methodology, it means science about method that can be used to do research activity. So research methodology can also interpreted as a study to uncover and explain nature and social symptoms in human lives, by using work procedure which is systematic, well- organized, and orderly and can be accounted scientifically.

According to Seliger and Shohamy (1989: 124) descriptive involves a collection of techniques used to specify, delineate, or describe naturally occurring phenomena without experimental manipulation.

In this study, the researcher uses a descriptive method to describe errors in using past tense in translating a narrative text into English. Nawawi (1996:73) says that descriptive method is the problem solving procedure which is investigated by describing the research object at the present based on the rising facts.

The technique of collecting data used in this research is using a test. Noll (1965: 13) states that "testing", as seems obvious, means the use of tests. It may mean testing the strength of materials, as in the case of textiles; it may mean testing a class in arithmetic, or it may mean testing an individual ${ }^{\text {le }} \mathrm{s}$ intelligence. It usually involves the use of some specific instrument or set of instruments to determine a certain quality or trait, or a series of such qualities or traits.

The researcher also uses continuum score data to count the result of the questionnaire. This technique is done by giving a list of the questions to the respondents. Then for each answer of the question the writer will make the alert scale. So, the researcher can take a conclusion to know the background of the difficulties of the students on using past tense in narrative text translation.

The technique of analyzing the data is based on the procedure of error analysis. This analysis is conducted through four main stages. These points are: the first is identifying the errors: The first step in analyzing learner errors is to identify them. This is in fact easier said than done. To identify errors we have to compare the 
sentences learners produce with what seem to be the normal or correct sentences in the target language which correspond with them. Sometimes this is fairly straight forward

The second is describing the errors: Once all the errors have been identified, they can be described and classified into types. There are several ways of doing this. One way is to classify errors into grammatical categories. We could gather all the errors relating to verbs and then identify the different kinds of verb errors in our sample, error in the past tense, for example. Another way might be to try to identify general ways in which the learners ${ }^{\text {ee }}$ utterances differ from the reconstructed target language utterances. Such ways include „omission"e,

„misinformation ${ }^{\text {ee }}$ and „misorderingee. Classifying errors in these ways can help us to diagnose learners ${ }^{\text {ee }}$ learning problems at any one stage of their development and also, to plot how changes in error patterns occur over time

The third is explaining the errors: The identification and description of errors are preliminaries to the much more interesting task of trying to explain why they occur. Errors are, to a large extent, systematic and, to a certain extent, predictable. Errors are not only systematic; many of them are also universal. Of course, not all errors are universal. Some errors are common only to learners who share the same mother tongue or whose mother tongues manifest the same linguistic property

The last one is evaluating the errors: Where the purpose of the error analysis is to help learners learn a second language, there is a need to evaluate errors. Some errors can be considered more serious than others because they are more likely to interfere with the intelligibility of what someone says. Teachers will want to focus their attention on these. Some errors, known as global error, violate the overall structure of a sentence and for this reason may make it difficult to process.

\section{RESEARCH FINDINGS AND DISCUSSIONS}

The data which had been obtained from the field were reported according to observation in the classroom, the test did by the students, and questionnaire. the material of the test given to the students is Indonesian language text that has to be translated into English narrative text. So, almost of the contents of the text are past tenses.

The researcher found some errors based on the indicator of $\mathrm{V} 2$ in narrative text translation such as: the first is the use of V2 (regular and irregular verb forms) in the sentence, the second is the use of past time marker like: yesterday, last week, etc, the third is the use of modal auxiliaries like: can, may, will, etc, and the last one is the use of helping verb like: negative sentence (did not, had not, etc), interrogative sentence ("did, were, etc." in front of the sentence.)

Based on the research that held by the researcher, the students make some kinds of errors. The percentages of the kinds of errors are: the first is kinds of errors based on the indicators: (1) Error on the use of V2: from the result above the researcher percentages the errors as: $\frac{390}{465} \times 100 \%=83.87 \%$, (2) Error of time marker: there is only one student that make this error. The percentage of the error is $\frac{1}{465} \times 100 \%=0.22 \%$, (3) Error of modal auxiliary: the total errors of modal auxiliary is 65 errors, so the percentage of the error is $\frac{65}{465} \times 100 \%=13.98 \%$, (4) Error of helping verb: there are nine students make this errors. the percentage of the error 
is $\frac{9}{465} \times 100 \%=1.94 \%$. The second is kinds of errors based on the causes: (1) Omission, 104 errors committed by the students. The percentage of the error is $: \frac{104}{184} \times 100 \%=56.52 \%$, (2) Addition, the total error of additions is 86 errors. The percentage of the error is $\frac{36}{184} \times 100 \%=19.57 \%$,

Overgeneralization, some students make this errors. The total errors are 44 errors. The percentage of the error is $\frac{44}{184} \times 100 \%=23.91 \%$.

Table 1. The Total Number of Errors

\begin{tabular}{|c|c|c|c|}
\hline No. & Indicator & Element & Total Score \\
\hline 1. & The use of V2 & $\begin{array}{l}\text {-The total number of verbs } \\
\text {-The correct form of V2 } \\
\text {-The incorrect form of V2 }\end{array}$ & $\begin{array}{c}480 \\
90 \\
390\end{array}$ \\
\hline 2. & The use of time marker & $\begin{array}{l}\text {-The total number of time marker } \\
\text {-The correct form of time marker } \\
\text {-The incorrect form of time marker }\end{array}$ & $\begin{array}{c}32 \\
31 \\
1\end{array}$ \\
\hline 3. & The use of modal auxiliaries & $\begin{array}{l}\text {-The total number of modal auxiliaries } \\
\text {-The correct form of modal auxiliaries } \\
\text {-The incorrect form of modal auxiliaries }\end{array}$ & $\begin{array}{l}96 \\
31 \\
65\end{array}$ \\
\hline 4. & The use of helping verb & $\begin{array}{l}\text {-The total number of helping verbs } \\
\text {-The correct form of helping verbs } \\
\text {-The incorrect form of helping verbs }\end{array}$ & $\begin{array}{c}32 \\
23 \\
9\end{array}$ \\
\hline
\end{tabular}

From the result above the researcher can see that the students are weak in translating Indonesian text into English text. As shown in the table the students make errors almost in every sentence. The students make errors on the use of V2. Most of the students do error on the use of V2, for example: *The body back to white. In the case of the sentence the student thinks that the word "back" as a verb, but it is not a verb, the correct verb is "became", and the correct sentence is "Their bodies became white". The other example is *It means they are very happy. There are two V2 error happens in this sentence, the first is the word "mean" should be "meant" then followed by "that they were" the correct V2 of "are" is "were". In the sentence of *Their body changes to grey. The student forgot to change V1 into V2. The word "changes" should be "changed". It means that the students lack of knowledge about the form of past tense verbs (regular, irregular verb, and the use of to be).

In the case of error of past time marker, almost all of the students make a correct past time marker. There was just one student did this error. *at a time.... The correct past time marker is "once upon a time, one day, and long time ago". The past time marker has to show that the story happened in the past.

Many errors of modal auxiliaries are committed by the students. Most of the students forget or don et understand to change the words of modal auxiliaries into past form ("can, may, will, must, etc" into "could, might, would, had to, etc.") for example: *they must play one by one. The word "must" should be "had to". So the correct sentence is "they had to play in turn". The other example is *...people can 
continue the activity back. The word "can" should be "could". So the correct sentence is "...people could continue the activity again". The error of modal auxiliary happens in this sentence too *They have to take turns to play. The correct past form of the word "have" is "had". Many students don ${ }^{\text {ee }}$ know the V2 of the modal auxiliary like (could, might, would, had to, etc. ).

The other error is error on the use of helping verb. The helping verb especially negative sentence, most of the students add "do not" in the sentence, whereas there should be "did not" because it is narrative text that should use past tense, for example: *His brother Tody don't the attitude of his brother. Some of the student forgets to add the word "did" before the word "not". For example: *His brother name Tody not like his brother attitude. The correct sentence is "His brother Tody did not like his brother attitude". Many students forgot to add to be on the sentence that there is no verb in the sentence. This case is called omission. As we know omission is the absence of an item that must appear in a well-formed utterance, for example: *but in that time just 1 slide board. In this sentence there is no verb, so the student had to add to be. The correct sentence is "but there was just one slide board at that time". The other example is *He not passions to wait his turn. There should a to be before the word "not". The correct sentence is "He was not patient to wait for his turn". The other example of omission error happens by other student for example: *His brother name Tody not like his brother attitude. The omission error committed by this student too *Lody is youngest cloud children, impatient. In this sentence there is no V2. The correct sentence is "Lody, the youngest cloud child was impatient". This means that the students don "t understand that in the sentence, there should the form of subject+ predicate (verb/ to be) + object. This case may happen because the student doesn "et know the correct form of V2. Whereas the knowledge of the form of past tense verb is the base knowledge that have to be understood by the students in translating Indonesian text into English narrative text. The other cause is the students forget to add the word to the sentence.

The highest number of students ${ }^{\text {ee }}$ errors based on the indicator is error on the use of V2, with total errors 390 errors (83.87\%). The errors of using past tense in narrative text translation most of the students make errors on the use of V2. 31 students made error in the sentence of "tubuhnya kembali menjadi putih" with the incorrect answer "the body back to white". The correct answer is "their bodies became white again". The other example is the sentence of "akhirnya mereka berkelahi" with the incorrect answer "finally they fight" / "finally they was fighted" / "finally they fighted". The correct answer is "finally they fought".

The kinds of errors based o the causes are the first is omission. Many students forgot to add to be on the sentence that there is no verb in the sentence. This case is called omission. As we know omission is the absence of an item that must appear in a well-formed utterance, for example: *but in that time just 1 slide board. In this sentence there is no verb, so the student had to add to be. The correct sentence is "but there was just one slide board at that time". The other example is *He not passions to wait his turn. There should a to be before the word "not". The correct sentence is "He was not patient to wait for his turn". The other example of omission error happens by other student for example: *His brother name Tody not like his brother attitude. The 
omission error committed by this student too *Lody is youngest cloud children, impatient. In this sentence there is no V2. The correct sentence is "Lody, the youngest cloud child was impatient". This means that the students don "t understand that in the sentence there should the form of subject+ predicate (verb/ to be) + object. This case may happen because the student doesn "et know the correct form of V2. Whereas the knowledge of the form of past tense verb is the base knowledge that have to be understood by the students in translating Indonesian text into English narrative text. The other cause is the students forget to add the word to the sentence.

The next error is addition. As the researcher explained in the chapter II, addition is the presence of an item which must not appear in a well-formed utterance, for example: *finally they are fight. The student gives an addition to be "are" in the sentence. The sentence doesn ${ }^{\text {et }} t$ need to be because there is a verb in the sentence. The correct sentence is "finally they fought". The other example in the same sentence is *And the end their was fought. The sentence doesn ${ }^{\text {ee }} \mathrm{need}$ to be because there is a verb in the sentence. The correct sentence is "finally they fought". The addition error happens in this sentence too *and it was came rain in the earth. The sentence doesn ${ }^{\text {ect }}$ need a to be because there is a verb in the sentence, so the to be "was" should be omitted.

The last error is overgeneralization as the expert talked about this error overgeneralization covers instances where the learner creates a deviant structure on the basis of his experience of other structures in the target language. For example: he can sings, we are hope, it is occurs, he come from. Richards (1984: 174). Some students committed this error. For example: *Finally they are fight. The example shows that the student makes a deviant structure. There is a verb in the sentence so the sentence does not need to be. The other example is *And the end their was foght. The example below is almost same with the previous example. The sentence does not need to be, because there is a verb in the sentence. The correct verb is "fought", and the correct sentence is "and finally they fought". The following example shows that the student makes her own word which is not appropriate with English vocabulary: *And finally they was fighted. There is no word "fighted" in English vocabulary. The student think that all of v2 are ended with -ed.

\section{CONCLUSIONS AND SUGGESTIONS}

From the result above the researcher concludes that the students still don ${ }^{\text {ee }} t$ understand the form of the past tense and how to make a good sentence. It maybe because of the first time they learn the forms of English language is not clear. The factors influencing errors of narrative translation of the students are (1) The students don "et understand the basic of making a correct sentence, (2) The students don ${ }^{e e} t$ understand enough the form of the past tense, (3) The students don et know the vocabulary / the words of V2, (4) The students don ${ }^{\text {ee }}$ understand how to apply modal auxiliaries,

(5) The students don't understand how to make negative sentence.

Based on the factors above the researcher suggests to teachers to overcome the problem in minimize the errors on the use of past tense in narrative text translation of the students, the researcher suggest to prepare well the material to give the explanation to the students. Explain clearly the use of V2 (regular and irregular verb forms) in the sentence, the use of past time marker like: yesterday, last week, etc., the use of modal auxiliaries like: can, may, will, etc. and the use of helping verb like: 
negative sentence (did not, had not, etc.), interrogative sentence ("did, were, etc." in front of the sentence). The students need some exercise to test how far are the students understand about simple past tense. Then the students can learn the narrative text, the purpose, the types, the features, and the structure, so that the students can apply the simple past tense into narrative text.

And suggests to students to learn more about the structure or the form of past tense, modal auxiliary and helping verb, memorize the V2 and stay focus on the structure when the teacher gives assignment to the students. Enrich the vocabulary and do some translation exercise will be more help the students when translating past tense narrative.

\section{BIBLIOGRAPHY}

Brown, Doughlas. (1987). Principles of Language Learning and Teaching. New York: Prentice-Hall, Inc

Corder, S. p. (1973).Introducing Applied Linguistics. Middlesex: Penguin Books Ltd (1993). Introducing Applied Linguistics. London: Pelican Book

Ellis, Rod. (1994). the Study of Second Language Acquisition. Edinburgh: Oxford University press (1997).Second Language Acquisition. New York: Oxford University Press

Freeman, Diane L. and Michael H. Long. (1991). an Introduction to Second Language Acquisition Research. United States of America: Longman Group UK limited

Nawawi, H. Hadari and Martini, H. Mimi. (1996). Penelitian Terapan.
Yogyakarta: Gadjah Mada University Press

Noll, Victor H. (1965). Educational Measurement. Boston: Michigan State University

Richards, Jack C. (1984). Error Analysis. Harlow: Longman Group Limited

Seliger, Herbert W. and Elana Shohamy. (1989). Second Language Research Methods. New York: Oxford University Press 